\title{
EFEITO DE DIFERENTES CONCENTRAÇÕES DE NITROGÊNIO E DE SACAROSE NA PROPAGAÇÃO in vitro DE TECA (Tectona grandis L.f.)
}

\author{
Dayane Ávila Fernandes ${ }^{1}$, Luana Pâmella de Almeida Azevedo ${ }^{1}$, Reginaldo Brito da Costa ${ }^{2}$ \\ ${ }^{1}$ Pós-Graduação em Ciências Florestais e Ambientais FENF/UFMT E-mail: dayavila1@hotmail.com / \\ eng.luanapamella@gmail.com \\ ${ }^{2}$ Faculdade de Engenharia Florestal FENF / UFMT. Av. Fernando Correa da Costa, nº 2367 - Bairro Boa Esperança, Cuiabá-MT \\ CEP: 78060-900 E-mail: reg.brito.costa@gmail.com.
}

\section{RESUMO}

A teca (Tectona grandis L. f.) é uma espécie arbórea considerada uma das madeiras mais valiosas do mundo. A micropropagação desse germoplasma surgiu como alternativa para a obtenção de mudas de alta qualidade, com características desejáveis e em escala comercial. Adicionalmente, pesquisas têm sido realizadas visando reduzir os custos da técnica. O presente estudo objetivou avaliar o desenvolvimento in vitro de Tectona grandis L.f., sob a influência de diferentes concentrações de nitrato de potássio $\left(\mathrm{KNO}_{3}\right)$ e de sacarose no meio de cultura. $\mathrm{O}$ delineamento experimental foi o inteiramente casualizado em esquema fatorial $5 \times 4$, sendo cinco concentrações de $\mathrm{KNO}_{3}(0,50,75,100$ e $125 \%)$ e quatro concentrações de sacarose $(12,18,24$ e 30 g. $\mathrm{L}^{-1}$ ), totalizando vinte tratamentos com dez repetições cada. Os explantes foram cultivados em meio MS, com pH ajustado para 5,8. O meio de cultura semi-sólido foi acrescido de 7 g.. ${ }^{-1}$ de ágar, e posteriormente esterilizado a $120^{\circ} \mathrm{C}$ e $1,5 \mathrm{~atm}$ por 25 minutos. Após a inoculação, os explantes foram mantidos por 45 dias em sala de crescimento com temperatura de $30 \pm 2{ }^{\circ} \mathrm{C}$ e fotoperíodo de $16 \mathrm{~h}$. Avaliaram-se as seguintes variáveis: matéria seca, comprimento da plântula e número de entrenós dos brotos. Para as três variáveis testadas, apenas a ausência de $\mathrm{KNO}_{3}$ se mostrou estatisticamente diferente das outras concentrações, mostrando que podem ser utilizadas menores doses desse macronutriente. Os resultados demonstraram a possibilidade de reduzir a concentração de sacarose, sem comprometer o desenvolvimento da teca. Os melhores resultados foram obtidos nas concentrações de 12,18 e 30 g.L. ${ }^{-1}$.

Palavras-chave: micropropagação, doses de nitrogênio, concentrações de $\mathrm{KNO}_{3}$

\section{EFFECT OF DIFFERENT NITROGEN AND SUCROSE CONCENTRATIONS FOR in vitro PROPAGATION OF TECA (Tectona grandis L.f.)}

\section{ABSTRACT}

Teak (Tectona grandis L.f) is considered one of the world's most valuable tree species for timber. Micropropagation has emerged as an alternative for obtaining high quality seedlings with desirable characteristics in a commercial basis. Studies are performed to reduce the technique costs. This trial evaluated in vitro development of Tectona grandis, under different concentrations of potassium nitrate $\left(\mathrm{KNO}_{3}\right)$ and sucrose in the culture medium. Experimental design was completely randomized in factorial scheme $5 \times 4$, with five concentrations of $\mathrm{KNO}_{3}(0$, $50,75,100$ and $125 \%$ ) and four concentrations of sucrose $\left(12,18,24\right.$ and 307 g. $\left.\mathrm{L}^{-1}\right)$, resulting in a total of twenty treatments with ten replicates each. The explants were kept on MS medium with $\mathrm{pH}$ adjusted to 5.8. To the semi-solid culture medium were added $77 \mathrm{~g} . \mathrm{L}^{-1}$ agar, and then sterilized at $120^{\circ} \mathrm{C}$ and $1.5 \mathrm{~atm}$ for 25 minutes. After inoculation, explants were kept for 45 days 
in a grow room at temperature of $30+2^{\circ} \mathrm{C}$ and photoperiod of $16 \mathrm{~h}$. Parameters evaluated were: dry matter, length and number of internodes of shoots. For the three variables, only the absence of $\mathrm{KNO}_{3}$ was statistically different from the other concentrations, showing that lower doses of this nutrient can be applied. Results showed to be possible to reduce sucrose concentration without compromising plant development. Best results were obtained at concentrations of 12, 18 and 307 g.L ${ }^{-1}$.

Key words: micropropagation, nitrogen levels, concentrations of $\mathrm{KNO}_{3}$

\section{INTRODUÇÃO}

A teca é uma espécie florestal de
grande porte pertencente à família Lamiaceae (Kew, 2009), que possui distribuição natural na Índia, Vietnã e Tailândia, sendo também encontrada em cultivo nos trópicos (Kok, 2009). Apresenta um conjunto de características que a torna uma das madeiras mais valorizadas mundialmente. A área de florestas plantadas com teca no Brasil atingiu, em 2009, uma estimativa de 65.240 ha, enquanto em 2008 o total foi de 58.810 ha. Tais áreas representam crescimento de $10,9 \%$ na área plantada deste grupo de espécies no país, indicando $o$ interesse crescente por tal gênero florestal, principalmente em função das expectativas de retorno financeiro em projetos com a mesma (Suzano Papel \& Celulose, 2009).

A micropropagação tem sido utilizada como um meio rápido de propagação vegetativa, permitindo a obtenção de um grande número de plantas com características desejáveis. O sucesso da técnica não depende somente dos fatores inerentes ao tecido vegetal (genéticos e fisiológicos), mas também das condições térmicas e luminosas em que a cultura é mantida, e do meio de cultura apropriado, que permite a indução, a multiplicação e o crescimento das brotações adventícias. Além disso, as exigências nutricionais requeridas para o crescimento de um tecido em condições "in vitro" variam de espécie para espécie, de variedade para variedade e até mesmo dentro da própria planta, mostrando a necessidade de otimização dos meios de cultura (Nagao et al., 1994).

O nitrogênio é o principal nutriente inorgânico em qualquer meio de cultura, independente da espécie e do objetivo do cultivo. É essencial por fazer parte de inúmeras estruturas orgânicas, compondo os nucleotídeos que formam os ácidos nucleicos (DNA e RNA), como também aminoácidos, que constituem as proteínas, estando presente ainda na própria molécula de clorofila (Russowski, 2001).

O potássio $(\mathrm{K})$ é um macronutriente essencial que atua na regulação da turgidez do tecido, ou seja, quanto maior a quantidade de potássio na célula, mais água será acumulada, criando condições favoráveis para as reações da fotossíntese e outros processos metabólicos. Atua também na abertura e fechamento de estômatos, ativação de inúmeras enzimas (algumas reações de fosforilação e síntese de proteínas), acúmulo e translocação de carboidratos, na formação de raízes e amadurecimento dos frutos (Malavolta, 1980; Taiz \& Zeiger, 2004). Sua carência pode causar clorose seguida de necrose nas folhas mais velhas (Malavolta, 1980).

O nitrato de potássio constitui a proporção mais elevada em relação aos demais reagentes na formulação de sais do meio MS (Murashige \& Skog, 1962). O reagente citado é utilizado na micropropagação como fonte de nitrogênio e potássio, sendo esses dois elementos 
encontrados em maiores quantidades nas plantas.

O sistema de iluminação das salas de crescimento torna insuficiente o crescimento autotrófico dos tecidos vegetais, e assim, os carboidratos são suplementados aos meios nutritivos como fonte adicional de energia. A sacarose é o carboidrato mais utilizado nos meios nutritivos, proporcionando as mais altas taxas de crescimento da maioria das espécies (Caldas et al., 1998). Para muitas espécies, a sacarose é empregada nos meios de cultura em uma concentração entre 2 e 4\%. Abaixo desta faixa pode ocorrer clorose generalizada da cultura e acima dela podem ocorrer problemas de excessivo potencial osmótico do meio, o que leva a deterioração das culturas (Grattapaglia \& Machado, 1990).

Considerando o exposto, o presente trabalho objetivou avaliar o desenvolvimento in vitro de Tectona grandis L.f., sob a influência de diferentes concentrações de nitrato de potássio $\left(\mathrm{KNO}_{3}\right)$ e de sacarose no meio de cultura.

\section{MATERIAL E MÉTODOS}

O experimento foi realizado no Laboratório Bioteca Ltda., situado em Várzea Grande, Mato Grosso, no período de agosto a setembro de 2010, com o clone A já estabelecido, proveniente das Ilhas Salomão.

$\mathrm{O}$ delineamento experimental foi inteiramente casualizado em esquema fatorial $5 \times 4$, sendo cinco concentrações de $\mathrm{KNO}_{3}(0,50,75,100$ e $125 \%)$ e quatro concentrações de sacarose $(12,18,24$ e 30 g. $\left.\mathrm{L}^{-1}\right)$, totalizando vinte tratamentos com dez repetições cada.

Os explantes foram cultivados in vitro, no meio de cultura MS, formulado por Murashige e Skoog (1962), com as variações nas concentrações de nitrato de potássio e de sacarose, e pH ajustado para 5,8. O meio de cultura semi-sólido foi acrescido de $7 \mathrm{~g} . \mathrm{L}^{-1}$ de ágar e posteriormente esterilizado a uma temperatura de $120{ }^{\circ} \mathrm{C}$ e 1,5 atm durante 25 minutos.

Os recipientes utilizados para inocular os explantes foram frascos de vidro com capacidade de $350 \mathrm{ml}$, diâmetro externo de $68 \mathrm{~mm}$ e altura de $128 \mathrm{~mm}$ (modelo Nadir Figueiredo Az-200®). Cada frasco continha $40 \mathrm{ml}$ do meio de cultura MS suplementado com as diferentes concentrações de nitrato de potássio e sacarose propostos anteriormente.

Para realizar este experimento foram repicados seiscentos segmentos nodais do clone A e inoculados em 100 frascos (sendo 6 explantes por frasco). As culturas foram mantidas na sala de crescimento em uma prateleira sob a temperatura de $28 \pm 2{ }^{\circ} \mathrm{C}$ e fotoperíodo de 16 horas.

Avaliou-se as variáveis matéria seca (mg), comprimento $(\mathrm{cm})$ e número de entrenós dos brotos. Os dados coletados foram submetidos a testes de homogeneidade de variâncias e normalidade. Comprovados estes parâmetros, os dados foram então submetidos ao teste de médias. Para a comparação das médias entre os tratamentos utilizou-se o teste de Tukey a $5 \%$ de probabilidade. A análise estatística foi realizada utilizando-se o sistema ASSISTAT 7.6 Beta - versão 2011 (Silva \& Azevedo, 2002).

\section{RESULTADOS E DISCUSSÃO}

Os resultados obtidos demonstraram não haver interação significativa entre a sacarose e o nitrato de potássio para nenhumas das variáveis consideradas. Porém, quando avaliadas separadamente, mostraram diferença significativa para quase todas as variáveis, exceto para o comprimento da plântula, na análise da quantidade de sacarose que mostrou resultados estatisticamente iguais. Além disso, as características estudadas foram afetadas a $1 \%$ de probabilidade (Tabela 1 ). 
Tabela 1. Resumo das análises de variância para comprimento de plântulas, número de entrenós e matéria seca e número de em função da concentração de nitrogênio e de sacarose.

\section{QUADRADOS MÉDIOS}

\begin{tabular}{ccccc}
\hline F.V. & GL & $\begin{array}{c}\text { Comprimento } \\
\text { das plântulas }\end{array}$ & $\begin{array}{c}\text { Número de } \\
\text { entrenós }\end{array}$ & $\begin{array}{c}\text { Peso seco } \\
\text { das plântulas }\end{array}$ \\
\hline Nitrogênio & 4 & $8.6268^{* *}$ & $11.5695^{* *}$ & $3.9444^{* *}$ \\
Sacarose & 3 & $1.0235^{\mathrm{ns}}$ & $8.5435^{* *}$ & $22.8158^{* *}$ \\
$\mathrm{~N}$ x S & 12 & $0.7582^{\mathrm{ns}}$ & $1.2701^{\mathrm{ns}}$ & $0.7676^{\mathrm{ns}}$ \\
Resíduo & 80 & 0.71227 & 0.43082 & 0.00002 \\
\hline \\
$\begin{array}{l}\text { CV }(\%) \\
\text { ** Significativo a 1\% de probabilidade } \\
\text { ns Não Significativo }\end{array}$
\end{tabular}

Para as três variáveis (comprimento, número de entrenós e peso seco), apenas a ausência de $\mathrm{KNO}_{3}$ se mostrou estatisticamente diferente das outras concentrações (Tabela 2).

No cultivo in vitro de teca, observouse que pode haver desenvolvimento utilizando menores doses de $\mathrm{KNO}_{3}$. Maldaner et al. (2006) reduziram a concentração de $\mathrm{N}$ para $50 \%$ daquela padrão do meio MS, associada a uma dose de sacarose até $45 \mathrm{~g} \mathrm{~L}^{-1}$, e isso favoreceu o crescimento em altura, número de segmentos nodais e brotações, bem como a produção de biomassa de ginseng brasileiro [Pffafia glomerata (Spreng.) Pedersen]. Além disso, Guimarães et al. (1999) observaram o maior comprimento de brotos utilizando $25 \%$ de nitrogênio e maior peso da matéria seca com $50 \%$, associadas a baixas concentrações de sacarose.

Porém, Santos et al. (2010) concluíram que até 120 dias de cultivo as microplantas de pupunheira (Bactris gasipaes Kunth), devem ser mantidas em meio de cultura com concentrações maiores de $\mathrm{KNO}_{3}$ que as recomendadas no meio MS, voltando para as doses recomendadas após esse período, facilitando a aclimatização e o desenvolvimento ex vitro. Essas informações mostram que o cultivo in vitro deve ser adequado para cada espécie, pois cada uma possui necessidades diferentes relacionadas aos nutrientes responsáveis pelo crescimento.

Os resultados obtidos com variação isolada de sacarose estão representados na Tabela 3.

Os dados obtidos possibilitaram observar que o comprimento não apresentou diferença significativa entre as concentrações testadas, demonstrando que concentrações menores também podem ser utilizadas. Moreira et al. (2007), ao avaliar diferentes concentrações de sacarose e frutose no desenvolvimento de plântulas de orquídea (Laelia purpurata Lindi var venosa $\mathrm{X}$ Cattleya warneri T. Moore alba), observaram o maior crescimento das plântulas no tratamento de 20 g.L-1 ${ }^{1}$ de sacarose, seguido pelos tratamentos de $10 \mathrm{e}$ 15 g.L-1 de sacarose e frutose. 
Tabela 2. Resultados obtidos das variáveis comprimento, número de entrenós e matéria seca para as diferentes concentrações de $\mathrm{KNO}_{3}(\%)$.

\begin{tabular}{cccc}
\hline $\begin{array}{c}\text { Concentração de } \\
\text { KNO3 }(\%)\end{array}$ & Comprimento & $\begin{array}{c}\text { Número de } \\
\text { entrenós }\end{array}$ & Matéria Seca \\
\hline 0 & $4.69100 \mathrm{~b}$ & $4.35550 \mathrm{~b}$ & $0.02295 \mathrm{~b}$ \\
50 & $5.74300 \mathrm{a}$ & $5.26350 \mathrm{a}$ & $0.02778 \mathrm{a}$ \\
75 & $5.82700 \mathrm{a}$ & $5.42150 \mathrm{a}$ & $0.02793 \mathrm{a}$ \\
100 & $6.12650 \mathrm{a}$ & $5.64600 \mathrm{a}$ & $0.02799 \mathrm{a}$ \\
125 & $5.85550 \mathrm{a}$ & $5.38050 \mathrm{a}$ & $0.02767 \mathrm{a}$
\end{tabular}

As médias seguidas pela mesma letra não diferem estatisticamente entre si. Foi aplicado o Teste de Tukey a 5\% de probabilidade.

Tabela 3. Resultados obtidos das variáveis (comprimento, número de entrenós e matéria seca) para as diferentes concentrações de sacarose $\left(\mathrm{g} \cdot \mathrm{L}^{-1}\right)$.

\begin{tabular}{cccr}
$\begin{array}{c}\text { Concentração de } \\
\text { Sacarose }\left(\text { g. L }^{-\mathbf{1}}\right)\end{array}$ & Comprimento & $\begin{array}{c}\text { Número de } \\
\text { entrenós }\end{array}$ & Matéria Seca \\
\hline 12 & $5.79200 \mathrm{a}$ & $5.52960 \mathrm{a}$ & $0.02270 \mathrm{~b}$ \\
18 & $5.76600 \mathrm{a}$ & $5.55720 \mathrm{a}$ & $0.02521 \mathrm{~b}$ \\
24 & $5.42040 \mathrm{a}$ & $4.93680 \mathrm{~b}$ & $0.02592 \mathrm{~b}$ \\
30 & $5.61600 \mathrm{a}$ & $4.83000 \mathrm{~b}$ & $0.03362 \mathrm{a}$ \\
\hline
\end{tabular}

As médias seguidas pela mesma letra não diferem estatisticamente entre si. Foi aplicado o Teste de Tukey a 5\% de probabilidade.

Ambos os resultados não são condizentes àqueles encontrados por Ribeiro et al. (2007), que ao testar diferentes fontes de açúcar em diversas concentrações no cultivo de manjericão roxo (Ocimum basilicum L.), constataram que as maiores alturas das brotações foram obtidas na adição de sacarose, nas doses de 30, 45 e 60 g.L-1. Esse comportamento mostra que as exigências nutricionais variam de acordo com a cultura.

Com relação ao número de entrenós, os melhores resultados foram obtidos com 12 e 18 g. L $^{-1}$ de sacarose. Resultados obtidos por Nicoloso et al. (2003) mostraram um número maior de segmentos nodais produzidos por plântulas de ginseng brasileiro [Pfaffia glomerata (Spreng.) Pedersen], com o uso de sacarose nas doses de 30, 45 e 60 g.L-1 . Rodrigues et al. (2007) ao testar as concentrações de 20, 30 e 40 g.L-1 de sacarose, observaram maior número de entrenós produzidos na concentração 30 g.L-1 de sacarose em plântulas de sempre viva (Alternanthera dentata Moench).

Para a variável matéria seca a concentração de 30 g.L $L^{-1}$ apresentou melhores resultados. Calvete et al. (2002) observaram o aumento da matéria seca no cultivo de morangueiro com o incremento da 
concentração de sacarose de 30 g.L $\mathrm{L}^{-1}$ utilizadas convencionalmente para $60 \mathrm{~g} . \mathrm{L}^{-1}$. Nesse caso, o maior conteúdo de sacarose no meio de cultivo correspondeu a uma maior concentração de carboidratos no tecido foliar. Com isso, as folhas tiveram capacidade de permanecer mais tempo na planta.

Porém, Dignart (2006) observou muitos aspectos positivos ao cultivar orquídeas in vitro com redução da concentração de sacarose de 30 para 15 g.L1. Outros estudos de micropropagação desta mesma família, dentre eles, Moreira et al. (2007), mostraram incremento de massa seca nas concentrações de 20 e 25 g.L $\mathrm{L}^{-1}$.

Apesar disso, alguns autores são contrários à idéia de redução da sacarose para a micropropagação. Ao manter os níveis de sacarose em torno de $3 \%$, a planta acumularia reservas de energia para sobreviver melhor ao ambiente na fase se aclimatização (Capellades et al., 1990). Nicoloso et al. (2003) constataram que nas concentrações de 30,45 e 60 g.L L $^{-1}$ de sacarose, foram obtidos maiores valores para massa fresca e seca da parte aérea, bem como da massa seca das raízes de ginseng brasileiro [Pfaffia glomerata (Spreng.) Pedersen].

É possível afirmar que podem ser utilizadas tanto a concentração convencional de sacarose (30 g.L $\mathrm{L}^{-1}$ ), como metade desta, no cultivo in vitro de teca. A sacarose eleva o custo da micropropagação porque aumenta a propensão à contaminação dos meios de cultura por microrganismos (Dirgnart, 2006). E considerando-se que a redução deste carboidrato auxiliou no desenvolvimento dos explantes observa-se que, embora o açúcar não seja o componente de maior custo na micropropagação, sua redução pode ser considerada economicamente desejável (Villa et al., 2006), além de fornecer aspectos positivos à produtividade.

\section{CONCLUSÃO}

A eficiência de concentrações de nitrato de potássio $\left(\mathrm{KNO}_{3}\right)$ e de sacarose menores do que aquelas usualmente propostas foram comprovadas sem comprometer o desenvolvimento dos clones de Teca, o que é desejável em termos econômicos.

\section{AGRADECIMENTOS}

Ao Laboratório Bioteca Ltda., pela disponibilização do espaço bem como o fornecimento de todos os materiais utilizados.

\section{REFERÊNCIAS BIBLIOGRÁFICAS}

CALDAS, L.S.; HARIDASAN, P.; FERREIRA, M.E. 1998. Meios nutritivos. In: TORRES, A.C.; CALDAS, L.S.; BUSO, J.A. (Eds.). Cultura de tecidos e transformação genética de plantas. Brasília: EMBRAPA-SPI/EMBRAPA-CNPH, p.87-132.

CALVETE, E. O.; KÄMPF, A. N.; SUZIN, M. 2002. Concentração de sacarose no enraizamento in vitro de morangueiro. Horticultura Brasileira, Brasília, v. 20, n. 2, p. 186-191.

CAPELLADES, M.; FOUNTARNAU, R.; CARULLA, C.; DEBERGH, P. 1990. Environment influences anatomy of stomata and epidermal cells of tissuecultured Rosa multiflora. Journal of the American Society for Horticultural Science, Alexandria, v.115, n.1, p.141145.

DIGNART, S.L. 2006. Luz e sacarose na micropropagação de Cattleya walkeriana: alterações anatômicas e fisiológicas. 130p. Dissertação (Mestrado em Fisiologia Vegetal) Universidade Federal de Lavras, Lavras, MG. 
GUIMARÃES, P. T. C.; PASQUAL, M.; MIRANDA, A. M. P. 1999. Efeito de diferentes concentrações de nitrogênio e de sacarose sobre a propagação in vitro de samambaia-espada [ Nephrolepis exaltata (L.) Schott ]. Ciência e Agrotecnologia, Lavras, v.23, n.2, p. 309-316.

GRATTAPAGLIA, D.; MACHADO, M.A. 1990. Micropropagação. In: TORRES, A.C.; CALDAS, L.S. Técnicas e aplicações da cultura de tecidos de plantas. Brasília: ABCTP/ EMBRAPACNPH. p.99-160.

KEW. Lamiaceae (Labiatae). 2009. Kew: Royal Botanic Gardens.

KOK, R. Tectona grandis (teak). 2009. Kew: Royal Botanic Gradens.

MALDANER, J.; NICOLOSO, F.T.; SANTOS, E.S.; FLORES, R.; SKREBSKY, E.C. 2006. Sacarose e nitrogênio na multiplicação in vitro de Pfaffia glomerata (Spreng.) Pedersen. Ciência Rural, Santa Maria, v.36, n.4, p.1201-1206.

MALAVOLTA, E. 1980. Elementos da nutrição mineral de plantas. São Paulo: Agronômica Ceres. 251 p.

MOREIRA, B. M. T.; TOMBA, E. C.; ZONETTI, P. C. 2007. Crescimento in vitro de plântulas de orquídea (Laelia purpurata Lindl var venosa X Cattleya warneri T. Moore alba) sob diferentes concentrações de sacarose e frutose. Sábios - Revista Saúde e Biologia, Campo Mourão, v. 2, n. 2, p. 16-21.

MURASHIGE, T.; SKOOG, F. A. 1962. revised medium for rapid growth and bioassays with tobacco tissue culture. Physiologia Plantarum, Copenhagen, v.15, p.473-497.

NAGAO, E. O.; PASQUAL, M.; RAMOS, J.D. 1994. Efeitos da sacarose e do nitrogênio inorgânico sobre a multiplicação "in vitro" de brotações de porta-enxerto de citros. Bragantia, Campinas, v.53, n.1, p.25-31.
NICOLOSO, F. T.; ERIG, A. C.; RUSSOWSKI, D.; MARTINS, C. F. 2003. Efeito de doses e fontes de carboidratos no crescimento de plantas de ginseng brasileiro [Pfaffia glomerata (Spreng.) Pedersen] cultivadas in vitro. Ciência e Agrotecnologia, Lavras, v. 27, n. 1, p. 84-90.

RIBEIRO, M. F.; DONINI, L.P.; SOUZA, J. A.; GUISSO, A.P.; FERREIRA MOURA,

I.; BOBROWSKI, V.L.; VIÉGAS, J. 2007. Influência de diferentes concentrações de sais de MS e açúcares no cultivo in vitro de manjericão roxo (Ocimum basilicum L.). Revista Brasileira de Biociências, Porto Alegre, v. 5, supl. 2, p. 57-59.

RODRIGUES, I. C. S.; RIBEIRO, M. V.; BRAGA, E. J. B. 2007. Multiplicação in vitro de Alternanthera dentata Moench em meio MS suplementado com diferentes concentrações de sacarose e BAP. In: CONGRESSO DE INICIAÇÃO CIENTÍFICA, 16., 2007, Pelotas. Resumos... Pelotas, UFPEL.

RUSSOWSKI, D. 2001. Nitrogênio e fósforo na micropropagação de Pffafia glomerata (Spreng.) Pedersen. 120f. Dissertação (Mestrado em Agronomia) - Programa de PósGraduação em Agronomia, Universidade Federal de Santa Maria.

SANTOS, T.L.; ALMEIDA, C.V.; BRONDANI, G.E.; ALMEIDA, M. 2010. Nitrato de amônio e nitrato de potássio no desenvolvimento in vitro de embriões somáticos de pupunheiras. Ciência Rural, Santa Maria, v.40, n.7, p. 1655-1659.

SILVA, F. A. S.; AZEVEDO, C. A. V. 2002. Versão do programa computacional Assistat para o sistema operacional Windows. Revista Brasileira de Produtos Agroindustriais, Campina Grande, v.4, n.1, p71-78.. 
SUZANO PAPEL E CELULOSE. Capítulo I - Florestas plantadas no Brasil. 2009. Disponível em: http://www.ciflorestas.com.br/arquivos/ doc florestas_2009_31555.pdf

TAIZ, L.; ZEIGER, E. 2004. Fisiologia vegetal. 3. ed. Porto Alegre: Artmed. $719 \mathrm{p}$.
VILLA, F.; PASQUAL, M.; PIO, L. A. S.; ASSIS, F. A. 2006. Multiplicação in vitro de porta-enxerto de videira em variações do meio MS. Acta Scientiarum Agronomy, Maringá, v. 28 , n. 3, p. 345-349. Wiley \& Sons. 1016 p. 